\title{
Effects of Auxin and Cytokinin on In Vivo Adventitious Shoot Regeneration from Decapitated Tomato Plants
}

\author{
Takahiro Tezuka, Masashi Harada, Masahumi Johkan', \\ Satoshi Yamasaki ${ }^{2}$, Hideyuki Tanaka, and Masayuki Oda ${ }^{3}$ \\ Graduate School of Life and Environmental Sciences, Osaka Prefecture \\ University, Sakai, Osaka 599-8531, Japan
}

Additional index words. callus, complete decapitation method, histological observation, lateral branch, plant growth regulator, Solanum lycopersicum

\begin{abstract}
Adventitious shoots can be regenerated from the cut surface of the primary shoot and lateral branches in decapitated plants in vivo. This inherent regenerative ability of plants is useful for mass propagation. In the present study, we conducted histological observations of shoot regeneration and applied auxin and cytokinin to decapitated seedlings in four tomato cultivars. The cultivars produced different numbers of adventitious shoots after decapitation; 'Petit' produced the largest number of adventitious shoots $(78.5 \pm 10.2)$ and 'Momotaro' produced the fewest $(12.1 \pm 3.3)$. Histological observation of 'Petit' revealed that adventitious shoots regenerated from calli formed at the cut surface of stems. Adventitious shoot formation was inhibited by the presence of lateral branches. Shoot regeneration was prevented by application of 1-naphthaleneacetic acid to 'Petit'. Application of 6-benzyladenine promoted shoot regeneration in 'Momotaro'. These results suggest auxin synthesized de novo from the lateral branches inhibited shoot regeneration after decapitation and endogenous cytokinin might stimulate shoot regeneration. Chemical names: 1-naphthaleneacetic acid (NAA); 6-benzyladenine (BA)
\end{abstract}

Traditional vegetative propagation methods such as cuttings and grafting are important for propagation of plant cultivars heterozygous for some loci, because those loci segregate in selfed progeny. In tomato (Solanum lycopersicum), although cultivars are usually propagated from seeds, several cultivars propagated by vegetative methods have been developed recently in Japan, i.e., 'Koshi-no-Ruby' developed at Fukui Prefectural University and 'Koshi-no-Ruby Sayaka' and 'Koshi-no-Ruby Urara' developed in Fukui Prefecture (Sato et al., 2009). However, the efficiency of vegetative propagation by traditional methods is insufficient for mass propagation of plantlets.

Adventitious shoots can be regenerated from cut surfaces of hypocotyls or stems in decapitated plants in vivo. Such a phenomenon has been observed in many plant species, including tomato (Harada et al., 2005; Steinitz et al., 2006), Cucurbita pepo (Amutha et al., 2009), and poinsettia (Nielsen et al., 2003). Taking advantage of the inherent regenerative ability of plants, a new method, termed the complete decapitation method

Received for publication 5 Aug. 2011. Accepted for publication 4 Oct. 2011.

${ }^{1}$ Present address: Graduate School of Horticulture, Chiba University, Matsudo, Chiba 271-8510, Japan.

${ }^{2}$ Present address: Research Institute for Biological Science, Okayama, 7549-1, Yoshikawa, Kibityuotown, Kaga-gun, Okayama 716-1241, Japan.

${ }^{3}$ To whom reprint requests should be addressed; e-mailmoda@plant.osakafu-u.ac.jp.
(CDM) by Johkan et al. (2008c), was developed for mass propagation in tomato and poinsettia (Harada et al., 2005; Nielsen et al., 2003). This method enables in vivo adventitious shoot regeneration from stumps after decapitation of the primary shoot and all lateral branches. Harada et al. (2005) reported that 79 shoots were regenerated from the cut surface of primary shoots and lateral branches $36 \mathrm{~d}$ after CDM treatment without exogenous plant growth regulator (PGR) application in 'Petit' tomato.

Increasing the efficiency of adventitious shoot regeneration is important if CDM is to be applied to plantlet production in tomatoes. Etiolation of stems by covering the cut surface with an aluminum cap increased the number of regenerated shoots (Johkan et al., 2008a, 2008c, 2011). Foliar application of ascorbic acid after decapitation also promoted adventitious shoot formation (Johkan et al., 2008b, 2011). However, efficiency of shoot regeneration might be further improved by incorporation of other techniques such as treatment with PGRs. In plant tissue culture, organ differentiation is influenced by the relative concentration of PGRs in the culture medium; relatively high levels of cytokinin promote shoot formation, whereas high levels of auxin promote rooting, and intermediate levels induce callus formation (Thorpe, 2007). In CDM, adventitious shoots are likely to be regenerated from calli formed on the cut surface of primary shoots and lateral branches (Harada et al., 2005), which indicates there are similarities between shoot regeneration by CDM and tissue culture methods. Thus, PGRs might influence in vivo adventitious shoot formation from decapitated tomato plants.

In the present study, the number of adventitious shoots regenerated after decapitation was investigated using four cultivars of tomato. Histological observations were conducted to determine whether the shoots originated from calli formed on the cut surface of stems. It is well known that auxin is synthesized in the shoot apex (Leyser, 2005). Therefore, we investigated the effects of the presence of lateral branches on shoot regeneration. The PGRs 1-naphthaleneacetic acid (NAA) and 6-benzyladenine (BA), which are commonly used in tissue culture, were applied to decapitated plants as foliar sprays to understand the physiology of shoot regeneration by CDM and to improve the efficiency of shoot regeneration.

\section{Materials and Methods}

Plant materials. Four S. lycopersicum cultivars were used: 'Petit' (Takii Seed Co., Kyoto, Japan), 'TVR-2' (Sakata Seed Co., Kanagawa, Japan), 'Multi-First' (Takii Seed Co.), and 'Momotaro' (Takii Seed Co.). Seeds were placed on moist filter paper in petri dishes and kept in darkness at $30^{\circ} \mathrm{C}$ for several days. The germinated seeds were sown in a 72 -cell tray $(50 \mathrm{~mL} /$ cell $)$ or a 128 -cell tray (25 mL/cell) filled with a 1:1 (v/v) mixture of peatmoss (Super Cell-Top V; Sakata Seed Co.) and vermiculite (Nittai Co., Osaka, Japan) and were grown in a greenhouse under natural light conditions. Seedlings were fertigated at each watering with a nutrient solution containing $4.6 \mathrm{~mm}$ nitrogen, $1.3 \mathrm{~mm}$ phosphorus, $2.2 \mathrm{~mm}$ potassium, $1.1 \mathrm{~mm}$ calcium, and $0.4 \mathrm{~mm}$ magnesium.

Efficiency of shoot regeneration. When seedlings had developed more than eight true leaves, the primary shoot was decapitated between the seventh and eighth nodes with a sharp razor blade. All lateral branches that emerged after decapitation were excised at the base when they reached $5-10 \mathrm{~cm}$ in length to obtain a uniform cut surface area in these lateral branches. Shoots regenerated from the cut surface of primary shoots and lateral branches were harvested when they reached $3 \mathrm{~cm}$ in length (empirically, shoots of this length could form roots) for a period of 61 $\mathrm{d}$ after decapitation (DAD); regenerated shoots were harvested because they seemed to inhibit regeneration of additional new shoots. Eight seedlings were examined for each cultivar. During the experiments, the average maximum and minimum air temperatures in the greenhouse were 41 and $23{ }^{\circ} \mathrm{C}$, respectively.

Histological observations. Histological observations of shoot regeneration from the cut surface of the primary shoot were conducted on 'Petit' seedlings because this cultivar readily produced regenerated shoots. When 'Petit' seedlings had developed two or three true leaves, the primary shoot was decapitated between the cotyledonary and first nodes with a sharp razor blade. Lateral branches from the cotyledonary nodes were excised at the base at 10 DAD. During the experiments, the average 
maximum and minimum air temperatures in the greenhouse were 39 and $19{ }^{\circ} \mathrm{C}$, respectively.

Primary shoots were sampled at $0,5,10$, and $15 \mathrm{DAD}$ and the portion containing the cut surface was fixed in FAA (50\% ethanol:37\% to 40\% formaldehyde:glacial acetic acid, 90:5:5, $\mathrm{v} / \mathrm{v} / \mathrm{v}$ ) for at least $12 \mathrm{~h}$. The fixed samples were dehydrated through a graded ethanol-tertiary butanol series, embedded in paraffin, and sectioned at $16 \mu \mathrm{m}$. Sections were mounted on slides, deparaffinized in xylene, dehydrated through an ethanol series, stained with Delafield's hematoxylin, dehydrated through an ethanol series, infiltrated with xylene, and covered permanently. The sections were observed using a digital microscope (MIC-D; Olympus, Tokyo, Japan).

Effect of the presence of lateral branches. When 'Petit' seedlings had developed six or seven true leaves, the primary shoot was decapitated between the second and third nodes with a sharp razor blade. Lateral branches at the cotyledonary, first, or second nodes were retained, but other lateral branches were excised at the base at 14 DAD. Shoots regenerated from the cut surface of primary shoots and lateral branches were harvested when they reached $3 \mathrm{~cm}$ in length for a period of $28 \mathrm{~d}$ after excision of lateral branches. Fifteen plants were examined per treatment. During the experiments, the average maximum and minimum air temperatures in the greenhouse were 38 and $16^{\circ} \mathrm{C}$, respectively.

Treatment with auxin and cytokinin. When 'Petit' and 'Momotaro' seedlings had developed more than seven true leaves, the primary shoot of the seedlings was decapitated between the fifth and sixth nodes. All lateral branches were excised when they reached $5-10 \mathrm{~cm}$ in length. The auxin NAA and the cytokinin BA (both obtained from Wako Pure Chemical Industries, Osaka, Japan) were dissolved in distilled water in a minimal amount of $99 \%$ ethanol and $1 \mathrm{~N} \mathrm{NaOH}$, respectively. Either NAA $(0.02$ or $0.12 \mathrm{~mm})$ or BA $(0.11$ or $0.22 \mathrm{~mm})$ was sprayed onto leaves of plants immediately

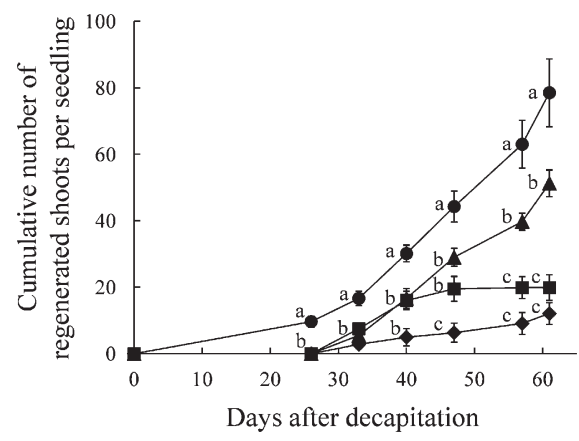

Fig. 1. Cumulative number of regenerated shoots per seedling in 'Petit' (circles), 'TVR-2' (triangles), 'Multi-First' (squares), and 'Momotaro' (diamonds) after the complete decapitation method treatment. Values are means of eight plants in which the primary shoot was excised between the seventh and eighth nodes; error bars represent the SE. Means in the same days with different alphabets are significantly different at $P<0.05$. after decapitation and then sprayed once a week over a period of $46 \mathrm{~d}$. For control plants, the same solvent solution used to dissolve NAA or BA was sprayed. NAA was applied to 'Petit' seedlings because this cultivar produced the highest number of adventitious shoots after CDM among the four cultivars tested (Fig. 1) and therefore 'Petit' was considered likely to be the most responsive cultivar. BA was applied to 'Momotaro' seedlings because this cultivar produced the lowest number of adventitious shoots after CDM among the cultivars tested (Fig. 1). Shoots regenerated from the cut surface of primary shoots and lateral branches were harvested when $3 \mathrm{~cm}$ in length at 53-67 DAD. Eight seedlings were examined per treatment. During the experiments, the average maximum and minimum air temperatures in the greenhouse were 30 and $15{ }^{\circ} \mathrm{C}$, respectively.

Statistical analysis. All data on the number of regenerated shoots were expressed as mean \pm SE from eight or 15 seedlings. The mean differences were statistically assessed at a $5 \%$ level by Tukey's test.
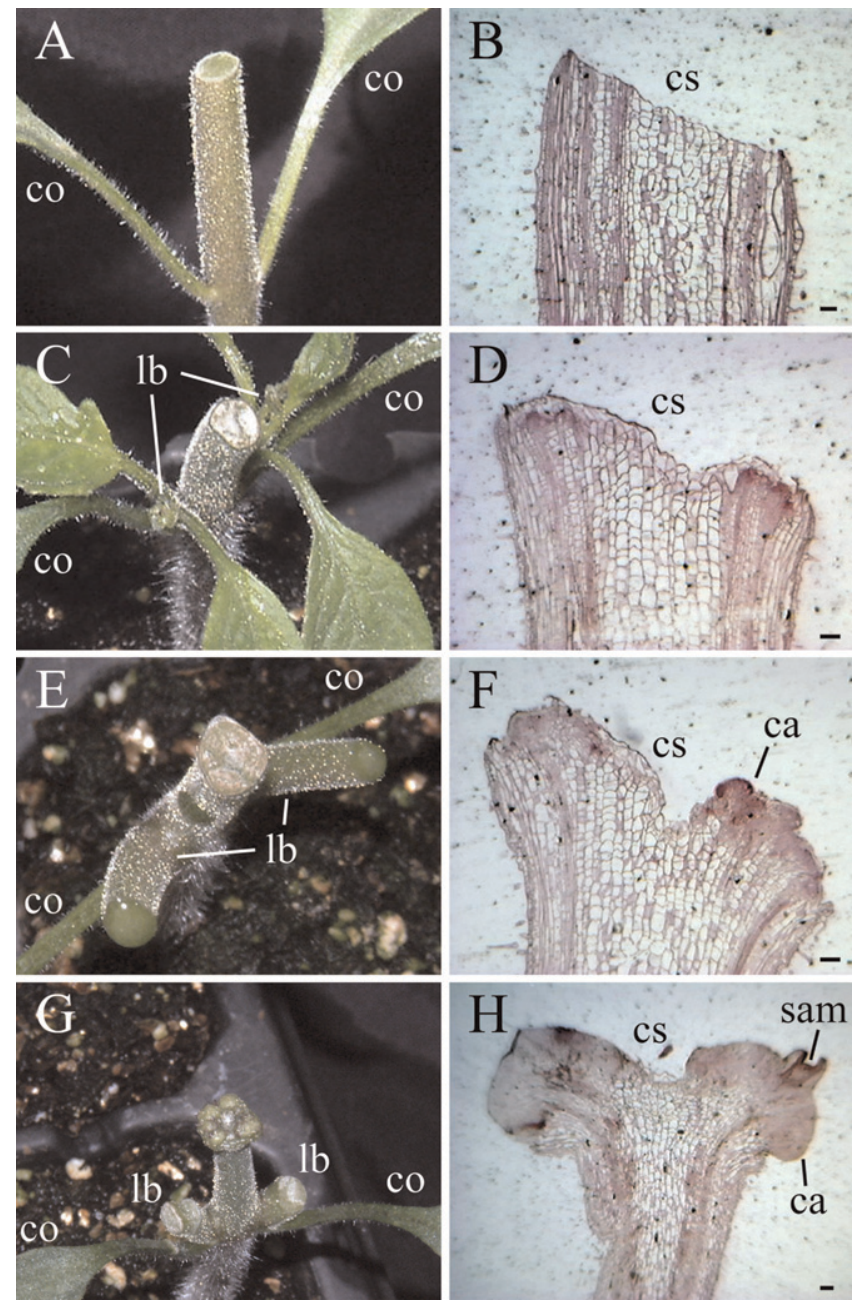

Fig. 2. Histological observation of in vivo shoot regeneration from the cut surface of the primary shoot in 'Petit'. External appearance of the primary shoot $(\mathbf{A}, \mathbf{C}, \mathbf{E}, \mathbf{G})$ and longitudinal sections of the primary shoot $(\mathbf{B}, \mathbf{D}, \mathbf{F}, \mathbf{H})$ of decapitated seedlings are shown. Similar results were obtained using three plants for each stage. (A-B) Seedlings at $0 \mathrm{~d}$ after decapitation (DAD); (C-D) seedlings at $5 \mathrm{DAD}$; (E-F) seedlings at $10 \mathrm{DAD} ;(\mathbf{G}-\mathbf{H})$ seedlings at $15 \mathrm{DAD} . \mathrm{co}=$ cotyledon; $\mathrm{lb}=$ lateral branch; $\mathrm{cs}=$ cut surface of the primary shoot; $\mathrm{ca}=$ callus; $\mathrm{sam}=$ shoot apical meristem. Bars $=300 \mu \mathrm{m}$. 
occurred (Fig. 2C-D). Callus was formed at the cut surface at 10 DAD (Fig. 2E-F). A shoot primordium emerged from the callus at $15 \mathrm{DAD}$ (Fig. 2G-H).

Presence of lateral branches decreased the number of adventitious shoots. Although 'Petit' seedlings with lateral branches at the cotyledonary or first nodes produced adventitious shoots, the percentage of seedlings that produced such shoots was markedly lower than that of seedlings lacking lateral branches (Table 1). At $28 \mathrm{~d}$ after excision of lateral branches (42 DAD), all seedlings lacking lateral branches produced adventitious shoots from the cut surface of the primary shoot. Some adventitious shoots also developed from the cut surface of lateral branches.

In addition, adventitious shoot formation was more strongly inhibited by the upper part of lateral branches than the lower part of lateral branches. Adventitious shoots regenerated from $60 \%$ of seedlings with lateral branches at the cotyledonary nodes and from $26.7 \%$ of seedlings with lateral branches at the first node (Table 1). These adventitious shoots regenerated from the cut surface of primary shoots, not from those of lateral branches. Seedlings with lateral branches at the second node produced only calli and no adventitious shoot developed.

The total number of adventitious shoots from all cut surfaces of a seedling was $3.3 \pm$ 0.4 when all lateral branches were excised. However, only $0.6 \pm 0.1$ and $0.4 \pm 0.3$ adventitious shoots were obtained from each seedling with lateral branches at the cotyledonary and first nodes, respectively (Table 1).

1-Naphthaleneacetic acid treatment decreased the number of adventitious shoots. All control 'Petit' seedlings produced adventitious shoots at 40 DAD (Fig. 3A). Adventitious shoots regenerated from $87.5 \%$ of the

Table 1. Effects of the presence of lateral branches on morphogenesis at the cut surface of primary shoots and lateral branches (LB) in 'Petit' tomato seedlings.

\begin{tabular}{|c|c|c|c|c|c|}
\hline \multirow[b]{2}{*}{ Remaining LB } & \multirow[b]{2}{*}{ Cut surface observed } & \multicolumn{3}{|c|}{$\begin{array}{l}\text { Percentage of seedlings } \\
\text { showing morphogenesis }\end{array}$} & \multirow{2}{*}{$\begin{array}{l}\text { Mean number of } \\
\text { adventitious shoots } \\
\text { per seedling }\end{array}$} \\
\hline & & None & Calli & $\begin{array}{l}\text { Adventitious } \\
\text { shoots }\end{array}$ & \\
\hline \multirow[t]{4}{*}{$\overline{\text { None }}$} & $\begin{array}{l}\text { LB at the cotyledonary } \\
\text { node }\end{array}$ & 20 & 73.3 & 6.7 & \\
\hline & LB at the first node & 80 & 6.7 & 13.3 & \\
\hline & LB at the second node & 80 & 13.3 & 6.7 & \\
\hline & Primary shoot & 0 & 0 & 100 & $3.3 \mathrm{a} \pm 0.4$ \\
\hline \multirow[t]{4}{*}{$\begin{array}{l}\text { LB at the cotyledonary } \\
\text { node }\end{array}$} & $\begin{array}{l}\text { LB at the cotyledonary } \\
\text { node }\end{array}$ & - & - & - & \\
\hline & LB at the first node & 100 & 0 & 0 & \\
\hline & LB at the second node & 100 & 0 & 0 & \\
\hline & Primary shoot & 20 & 20 & 60 & $0.6 \mathrm{~b} \pm 0.1$ \\
\hline \multirow[t]{4}{*}{ LB at the first node } & $\begin{array}{l}\text { LB at the cotyledonary } \\
\text { node }\end{array}$ & 100 & 0 & 0 & \\
\hline & LB at the first node & - & - & - & \\
\hline & LB at the second node & 100 & 0 & 0 & \\
\hline & Primary shoot & 66.6 & 6.7 & 26.7 & $0.4 \mathrm{~b} \pm 0.3$ \\
\hline \multirow[t]{4}{*}{ LB at the second node } & $\begin{array}{l}\text { LB at the cotyledonary } \\
\text { node }\end{array}$ & 100 & 0 & 0 & \\
\hline & LB at the first node & 100 & 0 & 0 & \\
\hline & LB at the second node & - & - & - & \\
\hline & Primary shoot & 60 & 40 & 0 & $0 \mathrm{~b}$ \\
\hline
\end{tabular}

Data were recorded $28 \mathrm{~d}$ after excision of lateral branches ( $\mathrm{n}=15$ plants).

${ }^{2}$ The number of adventitious shoots from all cut surfaces was counted, and the data are expressed as mean \pm SE. Means with different alphabets are significantly different at $P<0.05$.
In plant tissue culture systems, shoot regeneration capacity is genotype-dependent (Ohki et al., 1978). Shoots can regenerate from callus (Bhatia et al., 2004; Ohki et al., 1978) or directly (Bhatia et al., 2004; Dwivedi et al., 1990). High levels of auxin inhibit shoot formation (Matsuoka and Hinata, 1979; Tabei et al., 1991), whereas high levels of cytokinin promote shoot formation (Thorpe, 2007).

Different tomato genotypes respond uniquely to PGRs during organogenesis in vitro (Bhatia et al., 2004). Differences in the concentration and type of PGR influence both the percentage of responsive explants and the number of shoots produced by an explant (Bhatia et al., 2004). In CDM, different tomato genotypes might also respond uniquely to PGRs, and the number of adventitious shoots that develop in recalcitrant genotypes such as 'Momotaro' might be further increased by treatment with cytokinins other than BA. Therefore, further study is needed to determine whether cytokinin type influences shoot regeneration in different tomato genotypes treated by CDM.

The leaves of 'Petit' seedlings treated with $0.12 \mathrm{~mm}$ NAA turned yellow. When plants are treated with excess auxin, growth is disturbed and the plants is lethally damaged (Grossmann,
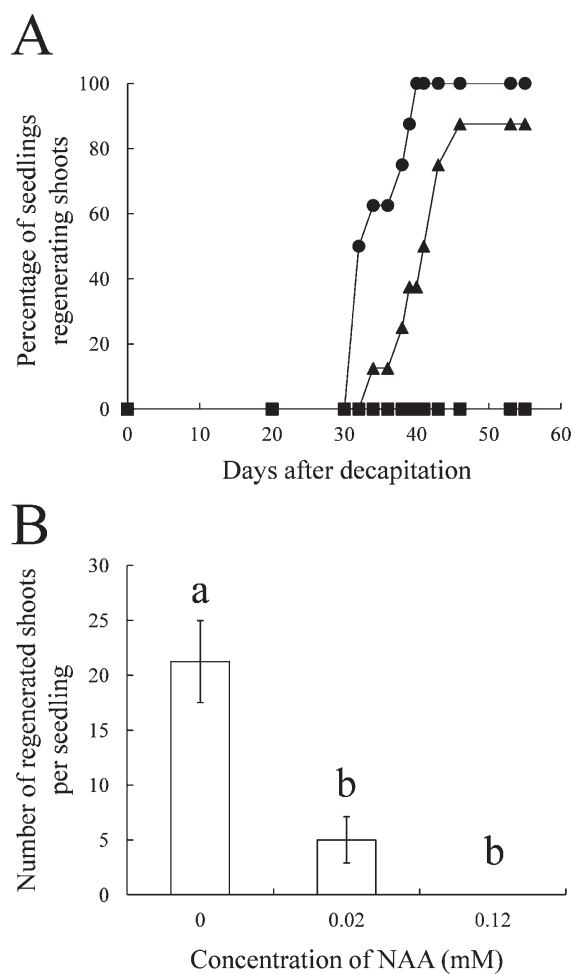

Fig. 3. Effect of 1-naphthaleneacetic acid (NAA) on in vivo shoot regeneration from the cut surface of the primary shoot and lateral branches in 'Petit'. Foliar treatment of either 0 (circles), $0.02 \mathrm{~mm}$ (triangles) or $0.12 \mathrm{~mm}$ (squares) NAA was applied to eight plants per concentration. (A) Percentage of seedlings with regenerated shoots after NAA treatment. (B) Number of shoots regenerated per seedling at 53-67 d after decapitation (DAD). Error bars represent the SE. Means with different alphabets are significantly different at $P<0.05$. 

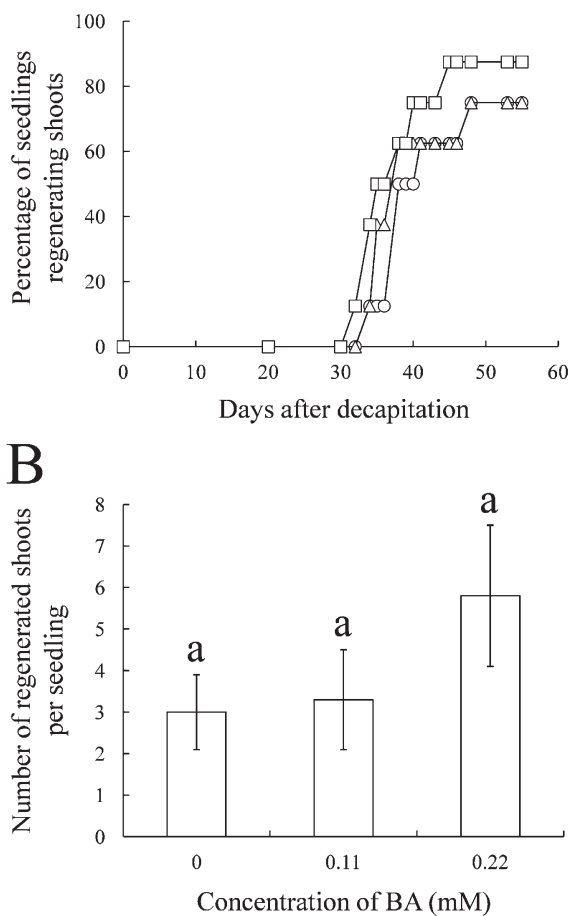

Fig. 4. Effect of 6-benzyladenine (BA) on in vivo shoot regeneration from the cut surface of the primary shoot and lateral branches in 'Momotaro'. Foliar treatment of either 0 (circles), 0.11 $\mathrm{mm}$ (triangles) or $0.22 \mathrm{~mm}$ (squares) BA was applied to eight plants per concentration. (A) Percentage of seedlings with regenerated shoots after BA treatment. (B) Number of shoots regenerated per seedling at 53-67 d after decapitation (DAD). Error bars represent the SE. Means with the same alphabets are not significantly different at $P<0.05$.

2010). Therefore, yellowing of leaves observed in the 'Petit' seedlings would be senescence by NAA at high concentration. Although the seedlings treated with $0.12 \mathrm{~mm}$ NAA survived during the experimental period, the senescence might somewhat influence the regeneration of adventitious shoots. Nevertheless, we concluded that NAA suppressed shoot regeneration, because the number of adventitious shoots significantly decreased by the $0.02 \mathrm{~mm}$ NAA treatment without disturbance of growth.

The mechanism of apical dominance and the previously mentioned organogenic responses in tissue culture provide clues to the likely mechanism of adventitious shoot formation after CDM treatment. In many plant species, a primary shoot shows apical dominance and axillary bud outgrowth is inhibited. After excision of the main shoot apex, the dormant axillary buds immediately begin to develop to replace the lost shoot apex. This phenomenon of apical dominance is regulated by auxin and cytokinin (Leyser, 2005; ShimizuSato et al., 2009).

The mechanism of apical dominance has been proposed based on recent studies in peas (Shimizu-Sato et al., 2009; Tanaka et al., 2006). In an intact plant, transport of basipetal auxin from the shoot apex represses expression of the adenosine phosphate-isopentenyl transferase (IPT) gene, which encodes a key enzyme in the cytokinin biosynthesis pathway in the stem. Consequently, axillary bud outgrowth is inhibited. After decapitation of the shoot apex, the auxin level in the stem decreases and repression of IPT gene expression is released. Subsequently, cytokinin is biosynthesized de novo in the stem and transported to dormant axillary buds, which induces outgrowth of axillary shoots. After development of the axillary buds, de novo synthesized indole-3-acetic acid (IAA) derived from the axillary shoot apex is transported to the stem and once more represses $I P T$ gene expression. In the present study, shoot regeneration from the cut surface of stems was inhibited by the presence of lateral branches, suggesting that IAA synthesized de novo from the lateral branches inhibited adventitious shoot formation. Furthermore, shoot regeneration was prevented by NAA application and promoted by BA application. Although involvement of cytokinin biosynthesis in shoot regeneration was unclear, endogenous cytokinin might stimulate shoot regeneration after CDM treatment.

Adventitious shoot formation in response to CDM in 'Petit' was more strongly inhibited by the upper part of lateral branches than the lower part of lateral branches. Two possible explanations might account for this difference in response. First, a higher amount of IAA might be synthesized in the upper part of lateral branches than in the lower part of lateral branches. Second, IAA transported to the primary shoot from the upper part of lateral branches was closer to the cut surface or might reach the cut surface more readily.

For practical use in mass propagation of tomato cultivars, vegetative methods to promote shoot regeneration were investigated in the present and previous studies (Johkan et al., 2008a, 2008b, 2008c, 2011). In addition to these studies, evaluation of the genetic stability of regenerated plants is required. Plants regenerated from tissue culture often show somaclonal variation (Larkin and Scowcroft, 1981), which has been reported in many plant species such as tomato (van den Bulk et al., 1990), rice (Ngezahayo et al., 2007), rye (de la Puente et al., 2008), and horseradish (Rostiana et al., 1999). Regeneration from callus might result in a higher percentage of plants that shows somaclonal variation than by direct regeneration from explants (Arene et al., 1993; Phillips et al., 1994; Pottera and Jones, 1991). Because shoots that developed after CDM treatment were regenerated from calli on the cut surfaces, plants regenerated from the adventitious shoots might show similar variability. The genetic stability of plants obtained after CDM treatment will be a focus of future investigations.

\section{Literature Cited}

Amutha, S., K. Kathiravan, S. Singer, L. Jashi, I. Shomer, B. Steinitz, and V. Gaba. 2009. Adventitious shoot formation in decapitated dicotyledonous seedlings starts with regeneration of abnormal leaves from cells not located in a shoot apical meristem. In Vitro Cell. Dev. Biol. Plant 45:758-768.

Arene, L., C. Pellegrino, and S. Gudin. 1993. A comparison of the somaclonal variation level of Rosa hybrida L. cv Meirutral plants regenerated from callus or direct induction from different vegetative and embryonic tissues. Euphytica 71:83-90.

Bhatia, P., N. Ashwath, T. Senaratna, and D. Midmore. 2004. Tissue culture studies of tomato (Lycopersicon esculentum). Plant Cell Tiss. Org. Cult. 78:1-21.

de la Puente, R., A.I. González, M.L. Ruiz, and C. Polanco. 2008. Somaclonal variation in rye (Secale cereale L.) analyzed using polymorphic and sequenced AFLP markers. In Vitro Cell. Dev. Biol. Plant 44:419-426.

Dwivedi, K., P. Srivastava, H.N. Verma, and H.C. Chaturvedi. 1990. Direct regeneration of shoots from leaf segments of tomato (Lycopersicon esculentum) cultured in vitro and production of plants. Indian J. Exp. Biol. 28:32-35.

Grossmann, K. 2010. Auxin herbicides: Current status of mechanism and mode of action. Pest Manag. Sci. 66:113-120.

Harada, M., M. Oda, G. Mori, and H. Ikeda. 2005. Mass regeneration of shoots from cut surfaces of stems in tomato stock plants. J. Jpn. Soc. Hort. Sci. 74:479-481.

Johkan, M., Y. Imahori, H. Furukawa, K. Mitsukuri, S. Yamasaki, H. Tanaka, and M. Oda. 2011. Effect of ascorbic acid and etiolation on antioxidant enzyme activity and phenylpropanoid metabolism during shoot regeneration from cut ends of tomato stems. J. Jpn. Soc. Hort. Sci. 80:45-51.

Johkan, M., G. Mori, Y. Imahori, K. Mitsukuri, S. Yamasaki, K. Mishiba, T. Morikawa, and M. Oda. 2008a. Shading the cut stems of tomato plants promotes in vivo shoot regeneration via control of the phenolic metabolism. Environ. Control Biol. 46:203-209.

Johkan, M., G. Mori, K. Mitsukuri, K. Mishiba, T. Morikawa, Y. Imahori, and M. Oda. 2008b. Effect of ascorbic acid on in vivo organogenesis in tomato plants. J. Hortic. Sci. Biotechnol. 83:624-628.

Johkan, M., G. Mori, K. Mitsukuri, K. Mishiba, T. Morikawa, and M. Oda. 2008c. In vivo shoot regeneration promoted by shading the cut surface of the stem in tomato plants. HortScience 43:220-222.

Larkin, P.J. and W.R. Scowcroft. 1981. Somaclonal variation-A novel source of variability from cell cultures for plant improvement. Theor. Appl. Genet. 60:197-214.

Leyser, O. 2005. The fall and rise of apical dominance. Curr. Opin. Genet. Dev. 15:468-471.

Matsuoka, H. and K. Hinata. 1979. NAA-induced organogenesis and embryogenesis in hypocotyl callus of Solarium melongena L. J. Expt. Bot. 30:363-370

Ngezahayo, F., Y. Dong, and B. Liu. 2007. Somaclonal variation at the nucleotide sequence level in rice (Oryza sativa L.) as revealed by RAPD and ISSR markers, and by pairwise sequence analysis. J. Appl. Genet. 48:329-336.

Nielsen, M.D., B. Farestveit, and A.S. Andersen. 2003. Adventitious shoot development from decapitated plants of periclinal chimeric poinsettia plants (Euphorbia pulcherrima Willd ex Klotsch). Europ. J. Hortic. Sci. 68:161-168.

Ohki, S., C. Bigot, and J. Mousseau. 1978. Analysis of shoot-forming capacity in vitro in two lines of tomato (Lycopersicon esculentum Mill.) and their hybrids. Plant Cell Physiol. 19:27-42.

Phillips, R.L., S.M. Kaeppler, and P. Olhoft. 1994. Genetic instability of plant tissue cultures: 
Breakdown of normal controls. Proc. Natl. Acad. Sci. USA 91:5222-5226.

Pottera, R. and M.G.K. Jones. 1991. An assessment of genetic stability of potato in vitro by molecular and phenotypic analysis. Plant Sci. 76:239-248.

Rostiana, O., M. Niwa, and W. Marubashi. 1999. Efficiency of inter-simple sequence repeat PCR for detecting somaclonal variation among leafculture-regenerated plants of horseradish. Breed. Sci. 49:245-250.

Sato, N., Y. Nomura, T. Tayasu, Y. Hatanaka, K. Kato, M. Saito, and T. Okuda. 2009. Breeding of ToMV resistant variety of middle-sized tomato, 'No.5' and 'No.11'. Bulletin of the Fukui Agricultural Experiment Station 46:2833 [in Japanese with English summary].

Shimizu-Sato, S., M. Tanaka, and H. Mori. 2009. Auxin-cytokinin interactions in the control of shoot branching. Plant Mol. Biol. 69:429-435.

Steinitz, B., A. Amitay, V. Gaba, Y. Tabib, M. Keller, and I. Levin. 2006. A simple plant regeneration-ability assay in a range of $\mathrm{Lyco}$ persicon species. Plant Cell Tiss. Org. Cult. 84:269-278.

Tabei, Y., T. Kanno, and T. Nishio. 1991. Regulation of organogenesis and somatic embryogen- esis by auxin in melon, Cucumis melo L. Plant Cell Rpt. 10:225-229.

Tanaka, M., K. Takei, M. Kojima, H. Sakakibara, and H. Mori. 2006. Auxin controls local cytokinin biosynthesis in the nodal stem in apical dominance. Plant J. 45:1028-1036.

Thorpe, T.A. 2007. History of plant tissue culture. Mol. Biotechnol. 37:169-180.

van den Bulk, R.W., H.J.M. Löffler, W.H. Lindhout, and M. Koornneef. 1990. Somaclonal variation in tomato: Effect of explant source and a comparison with chemical mutagenesis. Theor Appl. Genet. 80:817-825. 